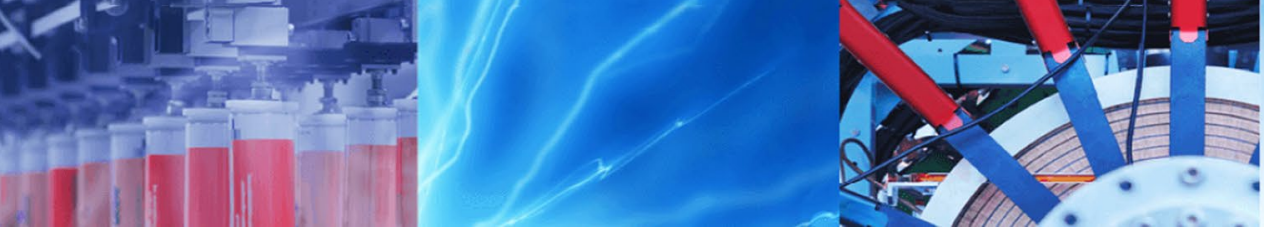

Research Article

\title{
Comparative effect of microbial induced calcite precipitate, cement and rice husk ash on the geotechnical properties of soils
}

\author{
Ibrahim Adewuyi Oyediran ${ }^{1}$ (i) . Oladunni Olufunmi Ayeni ${ }^{1}$
}

Received: 27 November 2019 / Accepted: 27 May 2020 / Published online: 3 June 2020

(c) Springer Nature Switzerland AG 2020

\begin{abstract}
This study presents experimental results of the investigation into the comparative effects of up to $15 \%$ by volume of microbial induced calcite precipitate (MICP), cement and rice husk ash (RHA) on the geotechnical properties of soils compacted at optimum molding water content (OMC) of the modified AASHTO (MA) energy level. This was with a view to determine the additive with the greatest positive influence in terms of improvement and possibly proffer an alternative to the costlier, environmentally unfriendly and more commonly used cement while advocating waste re-use. Geotechnical tests including consistency limits, compaction, permeability, unconfined compressive strength (UCS) and California bearing ratio (CBR) were conducted on the different mixtures. Results of this study indicate significant improvement in terms of workability, strength and permeability reduction which was observed for the stabilized soils. Addition of up to $15 \%$ of cement and MICP and $10 \%$ of RHA was noted to optimally improve the geotechnical properties of the soils. However, cement addition produced soils with the greatest strength, reduced plasticity index, OMC and permeability with increased maximum dry density, UCS and CBR when compared with MICP and RHA addition. Conclusively, while cement, irrespective of its environmental implications proved to be the best additive of the lot, RHA and MICP showed very good prospects as veritable environmental friendly and less costly alternatives.
\end{abstract}

Keywords Significant improvement · Environmental implications · Comparative effect · Microbial induced calcite precipitate

\section{Introduction}

Construction, rehabilitation and expansion of infrastructures are some of the many processes required to meet the ever-growing societal needs. However, these processes are directly limited by the unavailability of competent soils in desired locations where the various processes are carried out. The absence of such competent soils (often commonly characterized by low strength and high compressibility) in desired locations means soils with requisite properties either have to be imported (an expensive option as a result of haulage) or available soils on site need to be re-worked by means of stabilization to meet the required specifications. Most infrastructures constructed with materials which have the tendency to swell when their moisture content is allowed to increase do show signs of structural damage eventually leading to loss of lives and properties. According to Bello et al. [17], the high plasticity of a soil may cause cracks and damage on pavement, roadways, building foundations or any other civil engineering construction project. Hence it is obvious that not all soils are generally good materials necessitating improvement of their geotechnical properties through stabilization make them suitable.

Ali [8] noted that soil stabilization is a process to improve the physical and engineering properties of soil to obtain some predetermined targets while Akiije [3] opined that stabilization of soils could be achieved using

Ibrahim Adewuyi Oyediran, oyediranibrahim2012@gmail.com | 'Department of Geology, University of Ibadan, Ibadan, Nigeria. 
aggregate, bitumen, cement, salt, lime, sodium silicate, calcium chloride and resinous materials. Chemical compounds such as cement and lime (two main chemical additives used over the years for soils stabilization), are the two main materials used to improve the properties of the soil introducing them as fillers $[6,12,42]$. Other high silica content fillers such as fly ash, bitumen, asphalt etc. are also used to enhance soil strength. Constraints such as high cost of procurement and availability have hampered the use of these stabilizers for engineering works. Furthermore, the use of these artificial injection formulas often modifies the $\mathrm{pH}$ level of soil, contaminates soil and groundwater attributable to their toxic and hazardous characteristics $[29,34]$. Due to the high cost and demand of these materials, some underdeveloped and developing countries lack access to good roads and structures. In addition, the environmental issue arising from the use of cement has made it unpopular.

Authors including $[1,2,4,5,7,15,17,26,28,44,46,48$, 56] amongst others have shown the possibility of using agricultural waste materials, microorganisms and others as additives for soil stabilization. These materials have attracted the attention of researchers because of their low cost and high cementation reaction. Aparna [11] while using different proportions of RHA and a slight quantity of cement for soil stabilization, observed that UCS and CBR values of stabilized soil are significantly enhanced with RHA dosages. In a related study, Okafor and Okonkwo [44] investigated the effects of rice husk ash on some geotechnical properties of lateritic soil. The investigation included evaluation of properties such as compaction, consistency limits and strength of the soil with RHA content of 5, 7.5, 10 and $12.5 \%$ by weight of the dry soil. Results obtained showed that increase in RHA content increased the OMC but decreased the MDD. It was also observed that increase in RHA content, reduced plasticity and increased volume stability as well as the strength of the soil. 10\% RHA content was observed to be the optimum content. Oyediran and Fadamoro [47] accessed the response of highly plastic, compressible organic lbese shale to treatment with 2 to $20 \%$ by weight of rice husk ash (RHA) and coconut husk ash (CHA). Between 35 and $73 \%$ reduction in plasticity index respectively at optimum content between 6 and $10 \%$ with RHA and CHA was observed giving an indication of improvement in consistency and workability. Addition of $14 \%$ RHA and CHA resulted respectively, in $645 \%$ and $529 \%$ increase in UCS thus contributing to strength development but with RHA considered as the more effective additive. Furthermore, Montoya and Dejong [41] studied the stress-strain behaviour of sands cemented by MICP with Bacillus pasteurii. Triaxial tests on the soils in both undrained and drained conditions were made and the shear wave velocity through the samples was measured. Results show a transition from strain hardening to strain softening behaviour and thus corresponding transition of global to localized failure as calcite cementation increased. Moreover, Sharma and Ramkrishnan [52] carried out an experimental study on MICP and applied Bacillus pastuerii and urea-calcium chloride to improve two different types of fine grained soils. The effects of Bacillus pasteurii concentration, cementation reagent and duration of treatment on the soils improvement using unconfined compressive strength tests were examined with results showing that MICP application can enhance the unconfined compressive strength (1.5-2.9 times) for both types of soils. In addition, soil strength was observed to increase with increase in treatment duration. Eberemu [32] carried out an investigation on compacted lateritic soils treated with up to $16 \%$ rice husk ash (RHA), to assess its consolidation properties. The coefficient of volume compressibility (Mv) decreased and increased with higher RHA content; with effect of soil particle state with increasing pressure noticeable. However, the coefficient of consolidation (Cv) showed no observable trend with increased RHA content but generally increased with higher consolidation pressure on the dry and wet side of optimum compacted states. Chiet et al. [26] studied the feasibility of Bacillus subtilis and optimum reagents concentration used in microbial induced calcite precipitate (MICP) treatment of tropical residual soil. Measurements of soil shear strength and calcite content was performed and it was discovered that the cementation reagent concentration significantly affected the performance of MICP treatment. Results which showed both UCS and calcite content of treated soil had increased about $38 \%$ and $65.6 \%$ respectively, suggested that the most preferable MICP treatment reagents concentration is $0.25 \mathrm{M}$ with the presence of Bacillus subtilis; using these treatment parameters. However, the reduction in UCS value was manifested for those samples treated at higher reagents concentration $(0.35 \mathrm{M})$. This phenomenon was attributed to the salinity of reagents where high salinity is not favourable to the bacteria growth and microbial activity; subsequently, this resulted in a consequential decrease in shear strength of the treated soil.

This research work therefore presents the response of soils to RHA and MICP (additives proposed as alternatives to the environmentally unfriendly cement) compared with responses observed with cement. This is with a view to determine the additive with the greatest positive influence in terms of improvement in consistency, compaction, strength and permeability.

\section{Materials and methods}

Lateritic soil, Ordinary Portland cement (OPC), Rice Husk Ash (RHA) and Microbial Induced Calcite Precipitate (MICP) were used for this study. Disturbed and undisturbed 
samples of the reddish brown lateritic soil were purposively obtained from a depth of $1.5 \mathrm{~m}$ from test pits and subjected to geotechnical tests including grain size distribution analyses, consistency limits, specific gravity, permeability, compaction and CBR to classify and characterize the soils (Table 1). The soil samples obtained are organic materials of high plasticity, compressibility and hence high swelling potential, expected to lead to cracks and damages on pavement, roads, building and foundations. Specific gravity of 2.55 shows its organic nature [21] which may be due to the presence of organic impurities which affects the strength properties of the soil. Thus it can be said to be weak and not durable for construction work.

Ordinary Portland Cement (OPC) of Dangote Cement Brand with 42.5 MPa strength and a specific gravity of 3.1 was used to produce cement soil mixtures. According to Likhitha and Vidhyasagar Lal [19], cement consist mainly of lime, silica, alumina and iron oxide and some minor compounds, such as $\mathrm{MgO}, \mathrm{TiO}_{2}, \mathrm{Mn}_{2} \mathrm{O}_{3}, \mathrm{~K}_{2} \mathrm{O}$ and $\mathrm{Na}_{2} \mathrm{O}$; which usually amount to not more than a few percent of the weight of cement.

Furthermore, rice husks were sourced from a local milling site in Ago Aduloju, Ado-Ekiti, southwestern Nigeria. It was sun-dried for a day to facilitate the burning of the husks. The husks were burnt in open air and the resulting ash (RHA) was collected and sieved through sieve $75 \mu \mathrm{m}$.

Table 1 Geotechnical properties of the studied soil

\begin{tabular}{ll}
\hline Geotechnical properties & Quantity (\%) \\
\hline Grain size distribution & \\
Gravel & 8.30 \\
Sand & 35.90 \\
Fines & 55.80 \\
Atterberg limits & \\
Liquid limit & 62.00 \\
Plastic limit & 30.00 \\
Plasticity index & 32.00 \\
Casagrande chart classification & High plasticity/ \\
& compressibility \\
Compaction and Strength Parameters & \\
Level & Modified AASHTO \\
Maximum dry density & $1.64 \mathrm{~g} / \mathrm{cm}^{3}$ \\
Optimum moisture content & $18.00 \%$ \\
Unconfined compressive strength & $266.10 \mathrm{kPa}$ \\
Soaked CBR & $7.50 \%$ \\
Unsoaked CBR & $12.30 \%$ \\
Permeability & \\
Undisturbed & $5.20 \mathrm{E}-07$ \\
Disturbed & $1.90 \mathrm{E}-05$ \\
Other & \\
Specific gravity & 2.55 \\
\hline
\end{tabular}

The fraction that passed through the sieve was collected and kept in air-tight bag to avoid pre-hydration during storage. These fractions of RHA having a specific gravity of 1.26 were used throughout the tests because ultrafine size of RHA makes an excellent filler which goes into the micro voids giving high strength to the concrete or RHA mix [25]. Rice husk has a unique characteristic having high silica contents, high porosity, lightweight and very high external surface area which makes it a valuable material for industrial applications [54]. It is a carbon neutral green product obtained from the husk of rice. The pozzolanic activity of the ash is best obtained in the amorphous phase. Previous researchers including $[14,27,31,49]$ have shown that chemical composition of RHA to be used as a pozzolana, mainly compose of reactive silica (and free lime) which can chemically react with calcium hydroxide in presence of moisture at ambient temperature to form compounds possessing cementitious properties.

Moreover, MICP was introduced into the soil with the help of aerobic urease producing bacteria called Sporosarcina pasteurii (ATCC, 11859) and the prepared solution of cementation reagent. The cementation reagent composed of urea and calcium chloride at 5\% (0.05 M), 10\% (0.1 M) and $15 \%(0.15 \mathrm{M})$; and fixed amount of nutrient broth $(3.0 \mathrm{~g})$ because it is the most viable amount for survival of bacteria [9]. These helped in binding the soil particles for resistance and was done following the methods of Lee et al. [36].

\subsection{Sample preparation}

Soil samples collected were air-dried for 3 weeks (as opposed to the faster oven drying to obtain reliable result because some soils undergo irreversible changes when oven dried at temperature of $100^{\circ} \mathrm{C}$ to $110^{\circ} \mathrm{C}$ ). After the drying period, the soils were diaggregated and sieved with orderly arranged BS sieves; $4.76 \mathrm{~mm}, 2.36 \mathrm{~mm}, 1.18 \mathrm{~mm}$, $0.600 \mathrm{~mm}, 0.425 \mathrm{~mm}, 0.212 \mathrm{~mm}, 0.150 \mathrm{~mm}, 0.075 \mathrm{~mm}$. Weighted amounts of the dried soil samples $(500 \mathrm{~g})$ was poured into the stack of sieves and covered with a lid. This was later transferred to the mechanical sieve shaker and vibrated for $10 \mathrm{~min}$. Sieve analysis was done to determine the size range of the soil particles which is expressed as a percentage of the total dry weight. Consistency limits test was carried out to determine the liquid limit, plastic limit and the plasticity index. $50 \mathrm{~g}$ of soil that passed through the BS standard sieve of $0.425 \mathrm{~mm}$ were thoroughly mixed with a little distilled water to form a blended paste on a flat glass plat. A portion of the resulting mixture was used for the test. Furthermore, compaction tests was also carried out using the Modified AASHTO level of compaction (this was used because it is usually achievable with conventional field equipment [46], to determine the maximum 
dry density (MDD) and optimum moisture content (OMC) on BS mould. Hence compaction was achieved using $3 \mathrm{~kg}$ of air dried samples mixed thoroughly with $3 \%$ of water $(150 \mathrm{ml})$ and later compacted into a pre-weighed mould in 5 layers with each layer subjected to 55 blows of $4.5 \mathrm{~kg}$ rammer falling through a height of $0.45 \mathrm{~m}$ uniformly. The process was then repeated respectively after the addition of cement, RHA and treatment with MICP at 5, 10 and 15\% by volume.

CBR tests were performed on compacted samples in both soaked and unsoaked conditions. $6 \mathrm{~kg}$ of air-dried soil samples passing through sieve $0.425 \mathrm{~mm}$ was compacted into a mould in 5 layers with each subjected to 62 blows. The compacted samples were taken to the CBR test machine where the load was applied by a rigid plunger and the corresponding penetration of the soil was recorded. The test was done for both the top and the bottom of the samples in which each $0.5 \mathrm{~mm}$ penetration was recorded up to $6.0 \mathrm{~mm}$. Soaking of the samples was done with the compacted air-dried samples at optimum moisture content in a soaking tank for 4 days before the determination of the soaked CBR to simulate natural conditions, which may occur as a result of ingress of water below highway pavements. The process was then repeated respectively after the addition of cement, $\mathrm{RHA}$ and treatment with MICP at 5,10 and $15 \%$ by volume.

In the determination of UCS, $400 \mathrm{~g}$ of air-dried representative samples of the soil that passes through the BS sieve no. $0.425 \mathrm{~mm}$ was mixed with distilled water at optimum moisture content (using the Modified AASHTO level of compaction) and compacted in a cylindrical mould that was reduced to the required size of $76 \mathrm{~mm} \times 38 \mathrm{~mm}$ using the tamping rod at 4 layers. The samples were cured for 3,7 and 21 days and then loaded on the triaxial machine. The machine loaded the cylindrical sample by moving the piston rod downward at a constant rate. The load which corresponds to the deformation were measured and read from a steel proving ring until the sample failed. Stress was obtained through the applied force divided by crosssectional area of the sample while strain was obtained through the change in the original length divide by the original length of the sample. The stress and strain were then calculated and plotted to determine the unconfined compressive strength. This was also repeated for the soil-cement mixture, soil-RHA mixture and soil-MICP mixture in 5,10 , and $15 \%$ by volume.

For permeability test, permeameter, mixing container, water and stop watch, compaction mould and rammer were used. $2 \mathrm{~kg}$ of soil was compacted at Modified AASHTO level and were soaked in a water tank to allow for full saturation. The fully saturated test specimens were then connected to a permeant liquid (tap water) and using a stop watch, measurement of the time it takes for water to drop a certain distance $\left(\mathrm{h}_{1}-\mathrm{h}_{2}\right)$ was noted and hence permeability was calculated. The test was also repeated on soil mixed with cement, RHA and soil treated with MICP in 5,10 , and $15 \%$ by volume.

All the tests performed were in accordance with the BS 1377 [22] test protocols both in their natural state and after the addition of the additives. All experimental investigation involved multiple trials before comparing and determining the additives with the greatest effect on the soil strength.

\subsection{MICP specimen preparation}

In this study, prior to the MICP treatment, the bacterium was resuscitated on nutrient medium at the Environmental Microbiology and Biotechnology laboratory, University of Ibadan. One or two colonies of an 18-24 h old culture of the bacterium was used in the preparation of a suspension in normal saline, which was adjusted to $0.5 \mathrm{McF}$ arland standard for use in inoculating the set-up. Three buckets each filled with $15 \mathrm{~kg}$ of air-dried soil samples were hand tamped into desired densities. Serial dilution was performed on the incubated culture and the cementation reagent in $1 \mathrm{~L}$ of sterile distilled water at varying percentages of $5 \%, 10 \%$ and $15 \%$ of the components. These were then treated with the soil samples. The soil samples were then treated with the cementation solution at different concentration for 7 days at an interval of $24 \mathrm{~h}$. Faucet attached to the base part of the soil samples were opened after the treatment to drain out the excess solution from the setup. Subsequently, the soil samples were then air-dried for 2 weeks and subjected to the different analyses.

\section{Results}

The results of the different geotechnical test carried out on the soil treated with MICP, cement and RHA are presented on Tables 2 and 3.

Both the liquid limit and plasticity index reduced with increasing cement (up to 15\%), RHA (up to 10\%) and MICP (up to 15\%), while the plastic limit increased. Plasticity index and liquid limit of the soils mixed with cement reduced from 5 to $15 \%$. With regards to RHA addition, liquid limit and the plasticity index decreased as RHA increased from 5 to $10 \%$. At $15 \%$ addition, there was an increase in liquid limit, plasticity index and decrease in plastic limit. Moreover, the addition of MICP to the soil caused a continuous reduction in the liquid limits and plasticity index of the soil.

Compaction tests carried out on samples mixed with the additives (cement, RHA and MICP) at modified AASHTO energy level indicates decrease in OMC and increase in 


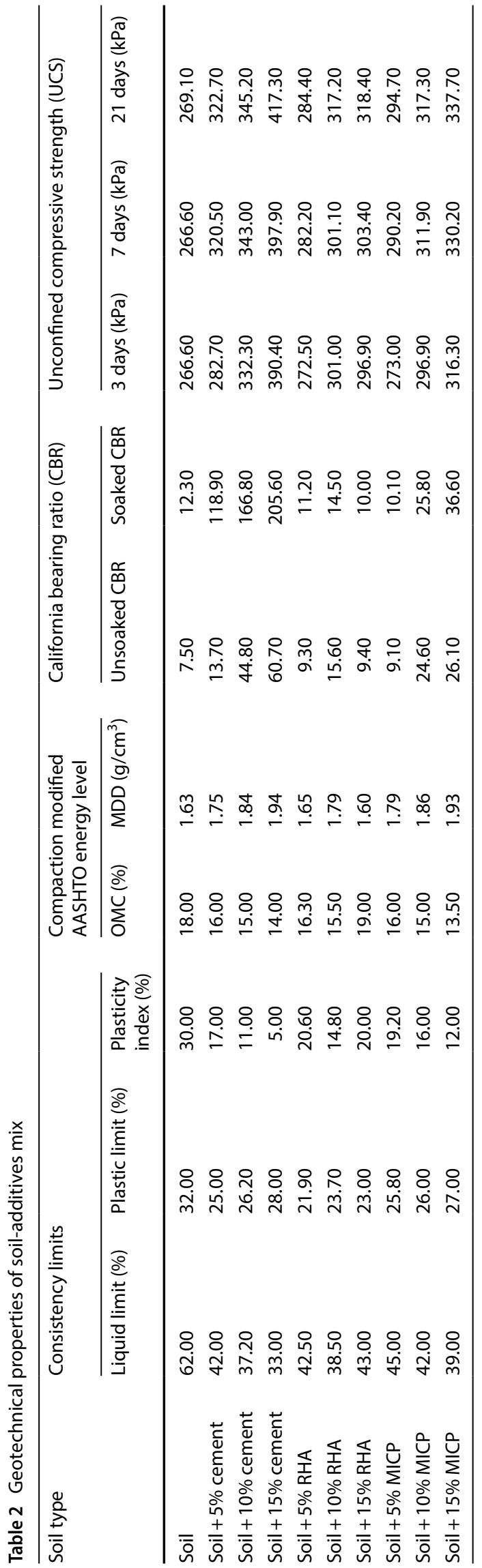

Table 3 Permeability test results

\begin{tabular}{ll}
\hline Soil type & Permeability $(\mathrm{cm} / \mathrm{s})$ \\
\hline Undisturbed soil & $1.90 \times 10^{-5}$ \\
Disturbed soil & $5.20 \times 10^{-7}$ \\
Soil + 5\% cement & - \\
Soil + 10\% cement & - \\
Soil + 15\% cement & - \\
Soil + 5\% RHA & $4.40 \times 10^{-7}$ \\
Soil + 10\% RHA & $4.20 \times 10^{-7}$ \\
Soil + 15\% RHA & $4.30 \times 10^{-7}$ \\
Undisturbed soil + 5\% MICP & $5.70 \times 10^{-6}$ \\
Undisturbed soil + 10\% MICP & $2.96 \times 10^{-6}$ \\
Undisturbed soil + 15\% MICP & $1.85 \times 10^{-6}$ \\
Disturbed soil + 5\% MICP & $1.89 \times 10^{-7}$ \\
Disturbed soil + 10\% MICP & $1.63 \times 10^{-7}$ \\
Disturbed soil + 15\% MICP & $1.23 \times 10^{-7}$ \\
\hline
\end{tabular}

MDD as the percentage of the additives increased. With increased cement treatment of up to $15 \%$, the OMC decreased while the MDD increased. On the other hand, treatment of the soil with RHA from 5 to $10 \%$ decreased the OMC from 16.3 to $15.5 \%$ and increased the MDD from 1.65 to $1.79 \mathrm{~g} / \mathrm{cm}^{3}$. At $15 \%$ RHA, MDD decreased (1.6 g/ $\mathrm{cm}^{3}$ ) with increased OMC (19\%). Furthermore, addition of MICP revealed that there was an increase in MDD with a decrease in OMC of the soil as the percentage of the cementation reagent increased.

The results of both soaked and unsoaked CBR tests upon addition of 5-15\% of cement, MICP and RHA are presented in Table 2. The unsoaked CBR of the soil-cement mix increased gradually as the percentages of cement increased. It is apparent that cement stabilization at $15 \%$ has higher unsoaked $(60.7 \%)$ and soaked CBR values (205.6\%) when compared to those of RHA and MICP. For unsoaked soils, the CBR value increased from 9.3 to $15.6 \%$ (for RHA content of 5-10\%) while for soaked CBR, the soil strength improved from 11.2 to $14.3 \%$. At 15\% RHA addition, unsoaked and soaked CBR reduced to $10 \%$ and $9.4 \%$ respectively. Addition of MICP to the soil revealed that cementation reagent of up to $15 \%$ yielded continuous increase in the CBR.

Results of the UCS test (Table 2.) shows continuous improvement in the compressive strength of the soil-cement mix as the percentage of cement increased from 5 to $15 \%$. Moreover, as the curing duration increased from 3 to 21 days, the strength of the soil-cement mix also increased. The highest value recorded for the curing durations was at $15 \%$ cement, which gave $390.4 \mathrm{kPa}, 397 \mathrm{kPa}$, and $417 \mathrm{kpa}$ for 3 days, 7 days and 21 days respectively. With regards to the addition of RHA, UCS increased as curing period increased. It was observed that for the 3 days 
curing period, the value increased at $5-10 \%$ but reduced at $15 \%$. For MICP addition, the UCS also increased with increase in cementation reagent.

The results of the Permeability tests upon addition of $5-15 \%$ of cement, MICP and RHA are presented in Table 3. $A$ reduction in permeability occurred upon soaking with cement. A general decrease in permeability with increased RHA content was observed. This same trend of great reduction in permeability was noticeable with MICP addition as the percentage content of the cementation reagent increased from 5 to $15 \%$.

\section{Discussion}

\subsection{Consistency limits}

The nature of changes in consistency of the soils with various percentages of cement, RHA and MICP are shown in Fig. 1. The reduction in plasticity index and liquid limit of the soils mixed with cement (from 5 to $15 \%$ ) is thought to be as a result of hydration of cement in reaction with water in the soil, forming calcium-silicate-hydrates and calcium alumina hydrate, thereby helping in the flocculation and aggregation of the soil particles [39]. The hydrated cement locks the soil particle together providing a permanent bound structure [58]. The decrease in liquid limit of the soil is in agreement with the results in Al-Rawas et al. [6]. The decrease in liquid limit and the plasticity index as RHA increased from 5 to $10 \%$ is attributable to the reaction between the RHA and the soil in which the RHA replaces the clay content in the soil $[11,46]$ thereby causing reduction in the liquid limit and plasticity index. The decrease in the liquid limit of the soil-RHA mix might be attributed to the fact that the rice husk ash, which is a pozzolanic material that is high in silica oxide, react with water to form compound possessing cementitious properties (calcium silicate) in soil particles [40]. This trend also conforms to findings of Muntohar and Hantoro [43]. However, the increase in liquid limit, plasticity index and decrease in plastic limit at $15 \%$ addition of RHA may be due to excess volume of $\mathrm{RHA}$ in the soil requiring more water for the RHA-soil mix $[32,44]$.

In terms of MICP treatment, a continuous reduction in the liquid limits and plasticity index of the soil was observed. As the percentage of the cementation reagent added to the soil increased from 5 to $15 \%$, the liquid limit and the plasticity index of the sample decreased. The decrease could be due to bacteria (which are aerobic bacterium that triggers the MICP and produces slime) in the soil, which helps in clogging the particles together, and trigger the cementation reagent to produce calcite. This ultimately leads to higher bonding between the soil particles, the higher bonding formation in soil then leads to increase in cohesive soil causing reduction in liquid limit of the soil [9]. The decrease could also be due to the precipitation of calcite, which results in the decrease in pore space of the soil particles with the pore spaces being filled with the calcite precipitate thereby binding the soil particles together [28]. Decrease in plasticity index shows that the engineering properties of the soils were improved as indicated by other researchers including $[32,44,46]$.

Casagrande classification chart (Fig. 2) shows that the natural soil exhibits high plasticity/compressibility which makes it unsuitable for construction works. However, after the treatment of the soil with the different additives; the soils exhibited medium plasticity/compressibility and hence medium swelling potential [24]. According to Bell [16] who classified plasticity using liquid limit values, while the natural soil possesses high plasticity the soils treated with RHA and MICP possess intermediate plasticity. Only the samples treated with $15 \%$ cement exhibits low plasticity. The maximum decrease in plasticity index for the soil was observed with the addition of $15 \%$ cement, $15 \%$ MICP and $10 \%$ RHA. In terms of consistency, it can therefore be inferred that the most effective additive is cement.
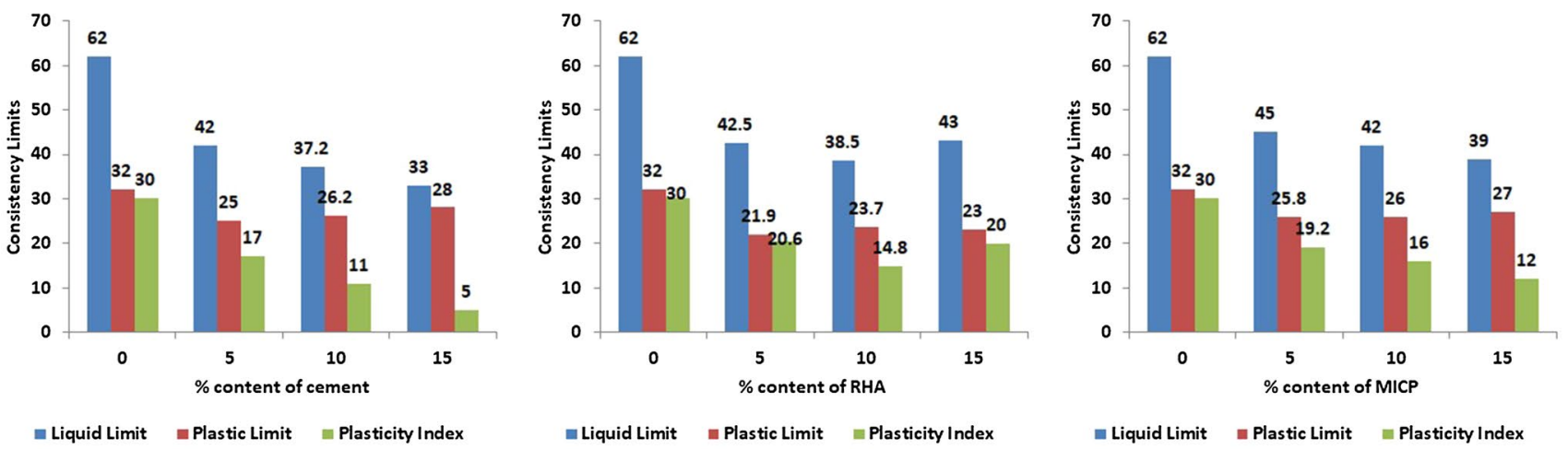

Fig. 1 Effect of the additives on consistency limits 


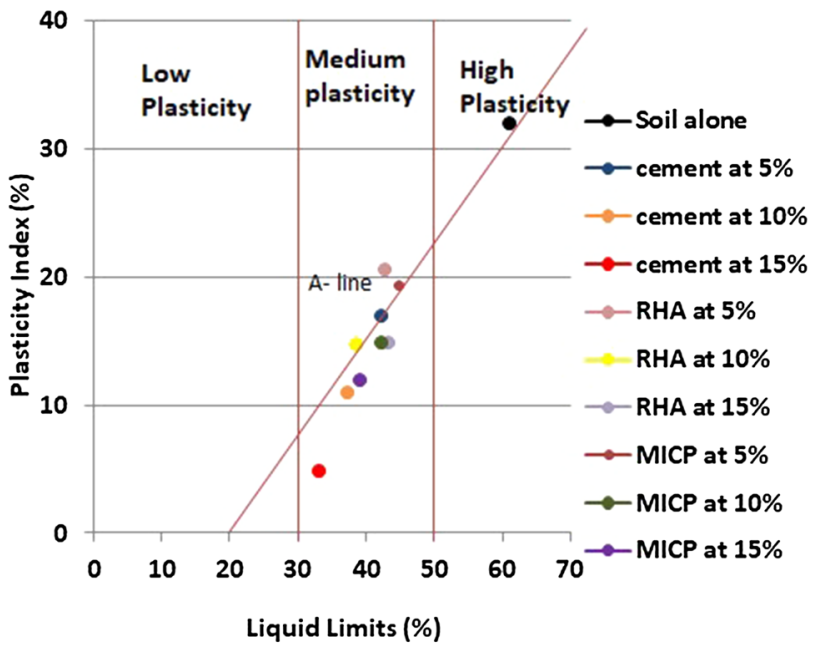

Fig. 2 Casagrande chart of the soil

\subsection{Compaction}

The increase in MDD as shown in the compaction test results (Fig. 3 ) is attributed to reaction of the mix with water; causing the fines in the soil to bind and form coarser particles with larger surface areas and to be firmly bonded as result of excess cement present in the material [42]. The decrease observed in OMC may be as a result of insufficiency of water in the system, which led to self-desiccation and consequently lower hydration. It is known that if no water movement to or from cement paste is permitted, the reaction of hydration use up the water until too little is left to saturate the soil surfaces and the relative humidity within the paste will decrease $[42,45]$.

The reversal in trend from decrease in OMC and increase in MDD (at 5-10\%) to decrease in MDD and increase in OMC at $15 \% \mathrm{RHA}$ is similar to those observed by Aparna [11]. The increased OMC with increased RHA content at $15 \%$ may be as a result of the extra water required for the pozzolanic reactions and increased affinity for water. This may also be attributable to the additional water held within the flocculent soil structure [46]. The additional water is accounted for as excess water absorbed or additional water being absorbed by the excess RHA as a result of its porous properties [15]. According to Eberemu [32], it could be due to the low specific gravity of the RHA (1.26) compared to that of soil (2.55) occupying larger spacing leading to the decrease in dry density [11]. However, increase in MDD may not be unconnected with the filling of the pores of the soil effectively with RHA. Increase in MDD further indicates the suitability of the energy of compaction [46].

Increase in MDD with a decrease in OMC (Fig. 3) of the soil as the percentage of the cementation reagent increased (using MICP) shows that there was an improvement due to the presence of calcite generated from the MICP process. The formation of calcite tends to bind the soil particles together and subsequently improved the stiffness and reduction in compressibility of the soil [51]. This led to increase in the MDD and reduction in the OMC. Calcite precipitation act as a bridge to bind the soil particles, which increased the strength of the treated soil [56]. Increase in MDD and decrease in OMC indicates a very good improvement in soil property and may be attributed to the positive response of the additives to the compactive effort. However, MICP as an additive produced the greatest effect on OMC and MDD when compared with cement and RHA.

\subsection{California bearing ratio (CBR)}

The results indicate cement addition (15\%) produced soils with higher soaked and unsoaked CBR (Fig. 4). After soaking the samples for $96 \mathrm{~h}$, the result revealed that CBR of the soil increased greatly, and the amount of water absorbed is very low which further stresses the fact that these soil-cement mix have low water retention capacity [35]. Decrease in CBR could be related to cement composed of calcium silicates and calcium aluminates, when combined with water, hydrates to form cementing compounds of calcium-silicate-hydrate and calcium-aluminate-hydrate
Fig. 3 Comparative effect of the additives on OMC and MDD of the studied soil
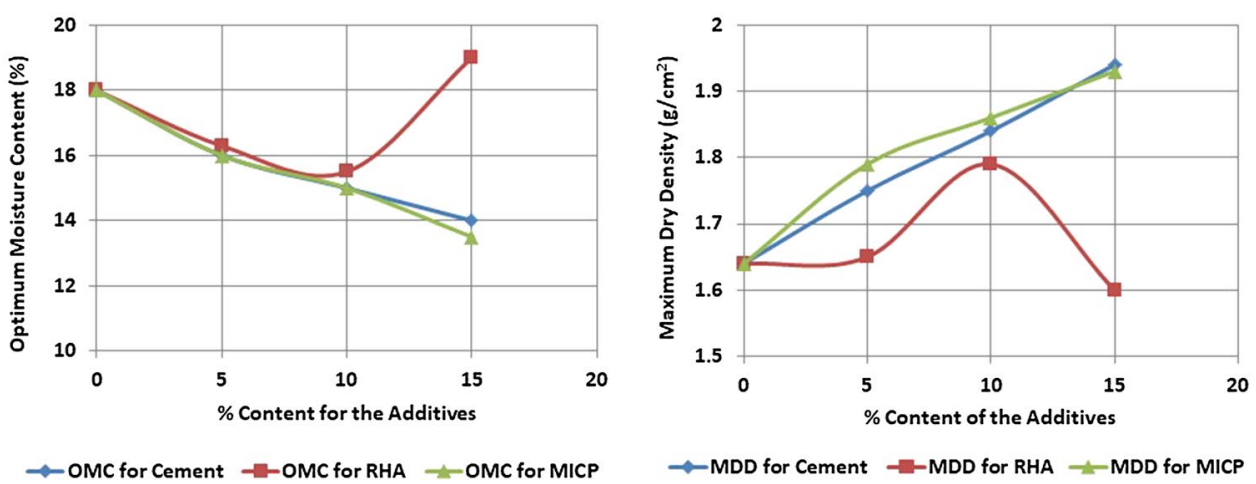

SN Applied Sciences A SPRINGER NATURE journa 
as well as excess calcium hydroxide [38]. These cementing compounds and excess calcium hydroxide make the granular soil to become a cementitious concrete and resistant, which makes the strength of the soil higher and can be for a long period of time. According to Mujedu et al. [42], increase in CBR could be that as soon as water is being added to the soil-cement mix, the cement began to hydrate which leads to increase in soil strength. It is therefore desirable to compact as soon as mixing is completed.

In addition, variation of CBR with increase in RHA from 5 to $10 \%$ shows an improvement in the soil strength and in its bearing capacity. The increase in CBR observed could be linked to the pozzolanic reactions that occur when RHA (highly reactive pozzolanic material that consists of high silica) is in contact with water to produce calcium silicate hydrates, and increases the strength of the soil [10]. The decrease in CBR could be due to extra RHA that could not be mobilized for the reaction which consequently occupies spaces within the sample. This reduced the bond in the soil-RHA mixture [44].

Samples treated with MICP showed great increment in unsoaked and soaked CBR. The MICP stabilization gained more strength when soaked for hours compared to unsoaked CBR. Increase in CBR might be due to the reaction of bacteria with the cementation reagent to produce calcite, which bind the soil together and fill the void spaces in the granular soil to increase its strength $[26,55]$. Dejong et al. [28] attributed increase in CBR to be due to higher relative density and increased number of contacts per particle within the dense sand, which contributed to the higher CBR value.

\subsection{Unconfined compressive strength}

Observed continuous improvement (Fig. 5) in strength as the percentage of cement increased from 5 to $15 \%$ as well as when curing duration increased is similar to observations by Koteswara et al. [35] and Shooshpasha and Shirvan [53]. This improvement can be linked to the hydration process that took place during the reaction of water with cement in the soil to form cementation compounds which glue the soil together and resulted into a hardening phenomenon [37]. Also, Saravut et al. [50] suggested that the increase in compressive strength could be due to a reduction of water content in the soil-cement mix. The reduction of the water content contributed substantially to the short-term improvement of the compressive
Fig. 4 Comparative effect of the additives on unsoaked and soaked CBR on the studied soil
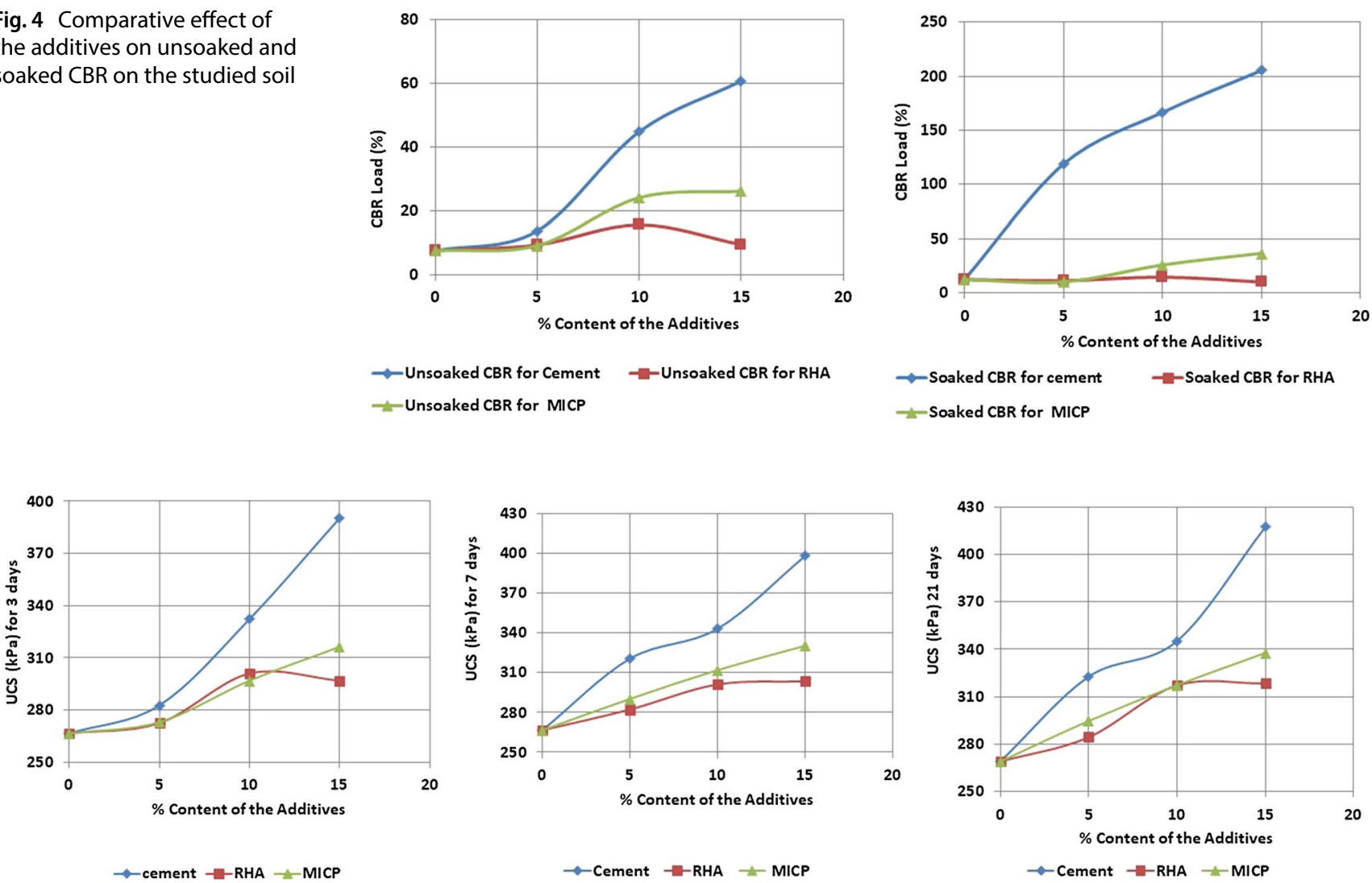

Fig. 5 Comparative effect of the additives on UCS cured for 3, 7, and 21 days

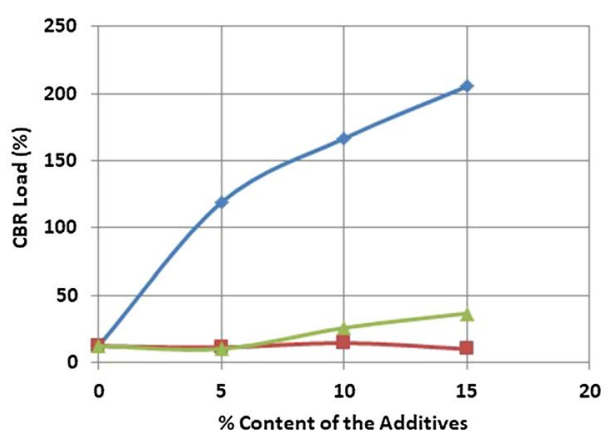

$\rightarrow$ Soaked CBR for cement $\quad \rightarrow$-Soaked CBR for RHA

-Soaked CBR for MICP 
strength while the long-term improvement was mainly caused by cementation.

The decrease in UCS observed for the 3 day curing period when RHA content increased to $15 \%$ might be due to excess RHA introduced into the soil, thereby forming weak bonds between the soil and the cementitious compounds formed [40]. It is also thought that the RHA content was in excess therefore requiring more time and water to react with the soil to be able to increase the strength of the soil [7]. This could be linked to the 3 days curing, when the highest UCS value at $10 \%(301 \mathrm{kPa})$ remains constant but increased when it was cured for 21 days. However, improvement in soil strength might be due to the high silica content in rice husk, which caused an increase in the strength of the soil-RHA mix [35]. Increase in UCS of soilRHA mix could also be linked to high amount of silica in RHA when reacting with calcium generating a pozzolanic material, which binds the soil particle together to increase the strength of the soil [21].

Furthermore, the response of the soil to MICP content in terms of UCS, showed increase in soil strength as the MICP added to the soil increased. Similar observation was reported by Hammes et al. [33] where shear strength and calcite content tend to increase with the increase of reagents concentration during MICP treatment. They attributed the increase in strength to be due to more percentage of cementation reagents which reacted with the bacteria in the soil to produce more calcite. As observed, the UCS of the treated soil samples with Sporascarcina pasteurii could be due to the calcite precipitation made of biochemical reactions between the microbes in the soil and the cementation reagent [34]. This means it can be attributed to the calcite precipitates produced in the presence of urease positive bacteria, which allowed the soil particles to bind with each other and filled up the remaining voids in the soil mass. These resulted into increase in soil strength. Furthermore, it was also observed that the shear strength increased (for MICP samples) as the curing duration increased from 3 to 21 days. Hence, the longer the curing duration, the more the MICP soil samples produce greater shear strength [55]. However, calcite minerals precipitated within the void spaces of soil particles increased the bond and thus improved the shear strength of the soil [23]. The additives (cement, RHA and MICP) can be said to have improved the UCS of the soil by acting as a modifier and an enhancer due to their effect on the soil.

\subsection{Permeability}

An impermeable soil was formed after soaking with cement for 7 days (Fig. 6). This is possibly because of the reactions that occurred when cement in the soil came in contact with water and hydrates to form calcium silicates hydrates, calcium aluminates hydrates and calcium hydroxide. These primary cementitious products govern the cemented soil while the calcium hydroxide reacts with the soil alumina and silica to form a secondary cementitious compound. This aid in binding the soil particle together to form a hard mass [57]. As observed, the cementation of the soil-cement mix which does not allow water might be due to some physical properties that may influence the mix when saturation is taken place [50]. The factors that influence physical properties of the soil-cement include soil type, amount of added cement, degree of mixing, time of curing, degree of compaction and moisture content.

The general decrease in permeability with increased RHA was rapid at RHA contents from 5 to $10 \%$ after which there was a slight increase at $15 \%$. The decrease in the coefficient of permeability of the soils also implies that the addition of RHA fills up the pore spaces in soil samples and increased the bond between the soil particles. This trend cannot be far-fetched since RHA contains $\mathrm{CaO}$ and other metallic oxides, which form hydroxides on reacting with water present in soil, cementing the soil particles [13]. Also decrease in permeability with increasing RHA content may be attributed to the formation of pozzolanic product due to clay and RHA reaction.
Fig. 6 Comparative effect of the additives on permeability
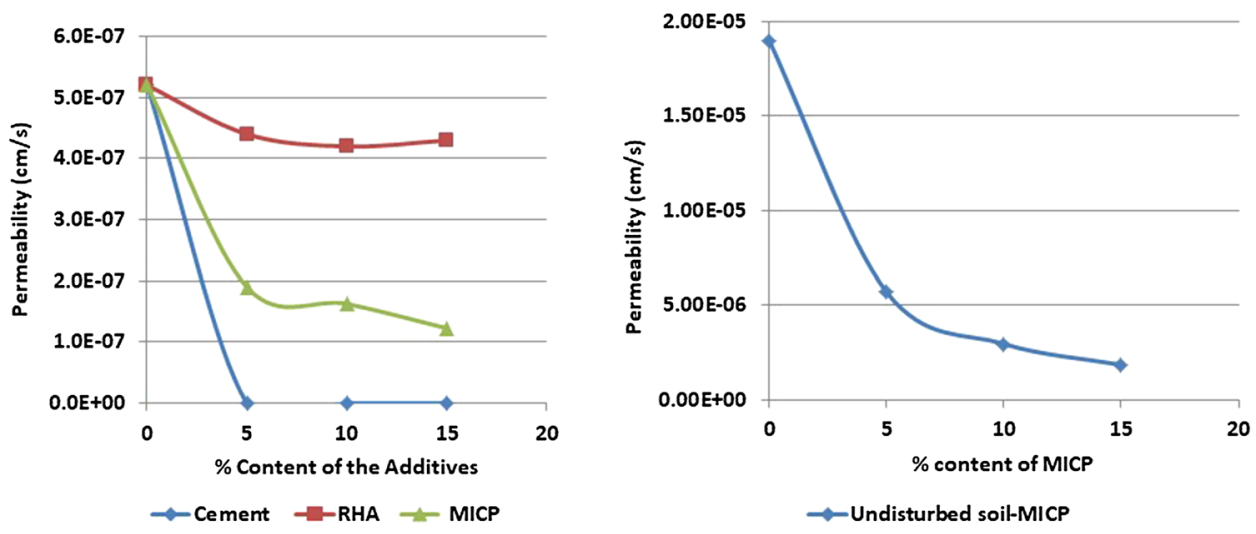

SN Applied Sciences A SPRINGER NATURE journa 
Furthermore, the permeability of soils treated with MICP, reduced greatly as the percentage content of the cementation reagent increased. It was observed that disturbed MICP treated soils reduced greatly than the undisturbed MICP treated soils. Whiffin et al. [56], Dejong et al. [28] and Dekuyer et al. [30] all agreed that the reduction is due to the formation of calcite precipitation near particle-particle contacts, reduced the pore throats and restrict water flow. In addition, it may be due to the fact that a setting time is allowed to ensure urea and bacteria propagation throughout the entire soil and a homogeneous accumulation of carbonate ion is obtained throughout the soil. When $\mathrm{Ca}^{2+}$ is supplied, only precipitation reaction takes place, as urea hydrolysis has already been completed. This leads to the stiffness of the soil, which inhibits the flow of water [18]. The highest reduction for the undisturbed and disturbed MICP samples was observed at $15 \%$ MICP content. This could be that under the same experimental condition, the $15 \%$ cementation reagent content provides a greater amount of ingredients (urea and ammonium) for promoting the MICP process compared with $5 \%$ and $10 \%$ [55]. In general, the additives reduced soil permeability with cement having the most beneficial effect of all the additives.

\section{Conclusion}

Investigations into the comparative effects of up to $15 \%$ by volume of microbial induced calcite precipitate (MICP), cement and rice husk ash (RHA) on the geotechnical properties of soils with a view to determine the additive with the greatest positive influence in terms of improvement and possibly proffer an alternative to the costlier, environmentally unfriendly and more commonly used cement while advocating waste re-use has led to the following conclusions;

Production of soils with improved strength with an increase in UCS, CBR, MDD and reduction in OMC. In addition, the additives added to the soils in amount not greater than $15 \%$ for cement, $15 \%$ for MICP and $10 \%$ for RHA (by volume) has beneficial effect on the strength of the soil. Furthermore, the improvement of the soil strength when mixed with the additives not only increases with the percentages of the additives but also increases with increase in the curing duration and gain more strength when soaked in water. Notably, higher content of cementation provides a greater amount of ingredients (urea and ammonium) for promoting the MICP process.

Moreover, reduction in plasticity index and permeability as the additives content increased was observed with the soils expected to exhibit low to medium welling potential and or compressibility. In general, the additives reduced soil permeability with cement generating the most beneficial effect of all the additives.

Addition of up to $15 \%$ of cement and MICP and 10\% of RHA was noted to optimally improve the geotechnical properties of the soils. However, cement addition produced soils with the greatest strength, reduced plasticity index, OMC and permeability with increased maximum dry density, UCS and CBR when compared with MICP and RHA addition. Cement proved to be the best additive when compared to MICP and RHA irrespective of its cost and environmental implications. However, RHA and MICP showed very good prospects as veritable environmental friendly, less costly alternatives and hence should be explored.

\section{References}

1. Abdu A, Kundiri AM, Yero SA (2017) Compaction behaviour of lateritic soils stabilized with blends of groundnut shell ash and metakaolin. J Environ Earth Sci 7(10):28-39

2. Adetoro AE, Dada OM (2015) Potentials of groundnut shell ash for stabilization of ekiti state soil, Nigeria. J Multidiscip Eng Sci Technol 2(8):2301-2304

3. Akiije I (2015) Comparison characterization of A-6(10) laterite soil stabilized with powermax cement and hydrated lime separately. Int J Eng Technol 5(7):392-401

4. Akiije I (2016) Stabilization of A-2-7(0) Laterite soil and strength characteristics using three selected cements individually. Int J Eng Technol 6(4):125-133

5. Akiije I (2016) Strength characterization of stabilized A-5(10), $A-7-5(16), A-4(3)$ and $A-2-7(1)$ laterite soils individually using supaset cement. Int J Sci Technol Soc 4(6):89-98. https://doi. org/10.11648/j.ijsts.20160406.12

6. Al-Rawas AA, Hago AW, Al-Sarmi H (2005) Effect of lime, cement and Sarooj (artificial pozzolanas) on the swelling potential of an expansive soil from Oman. Build Environ 40(5):681-687

7. Alhassan M (2008) Potentials of rice husk ash for soil stabilization. Assumpt Univ J Technol 11(4):246-250

8. Ali F (2012) Stabilization of residual soils using liquid chemical. Electron J Geotech Eng Sci Technol 2(1):102-110

9. Animesh S, Ramkrishnan R (2016) Study on effect of microbial induced calcite precipitates on strength of fine-grained soils. Perspect Sci 8:198-202

10. Anupam AK, Kumar PRN, Ransinchung GD (2012) Permeability study on fly ash and rice husk ash admixes with subgrade soil for pavement construction. In: Proceedings of international conference on advances in architecture and civil engineering (AARCV), paper ID TRA122, vol 1, pp 489-493

11. Aparna R (2014) Soil stabilization using rice husk ash and cement. Int J Civ Eng Res 5(1):49-54

12. Asgari MR, Baghebanzadeh AD, Bayat M (2015) Experimental study on stabilization of a low plasticity Clayey soil with cement/ lime. Arab J Geosci 8(3):1439-1452. https://doi.org/10.1007/ s12517-013-1173-1

13. Ayininuola GM, Olaosebikan OI (2013) Influence of rice husk ash on soil permeability. Int J Sci Technol 3(10):29-33

14. Bahrami A, Soltani N, Pech-Canul MI, González LA (2016) Development of metal-matrix composites from industrial/agricultural waste materials and their derivatives. Crit Rev Environ Sci Technol. https://doi.org/10.1800/10643389.2015.1077067 
15. Basha EA, Hashim R, Mahmud HB, Muntohar AS (2005) Stabilization of residual soil with rice husk ash and cement. Constr Build Mater 19(6):448-453

16. Bell FG (2007) Engineering geology, 2nd edn. ButterworthHeinemann Publishers, Oxford

17. Bello AA, Ige JA, Ayodele $H$ (2015) Stabilization of lateritic soil with cassava peels ash. Br J Appl Sci Technol 7(6):642-650

18. Bhattacharya S (2015) Numerical investigation of Biogrout: a new soil improvement method based on MICP. A Project Report Submitted to the Department of Civil Engineering National Institute of Technology, Rourkela, India

19. Bongu L, Vidhyasagar Lal N (2015) Stabilization of red soils with ordinary Portland cement. Int J Sci Eng Res (IJOSER) 3(11):3221-5687

20. Bowles JE (2012) Engineering properties of soil and their measurement, 4th edn. McGraw Hill Education (India) Private Limited, New Delhi

21. Brooks R (2009) Soil stabilization with fly ash and rice husk ash. Int J Res Rev Appl Sci 1(3):209-217

22. BS 1377 (1990) Standard methods of soils testing for civil engineering purposes. British Standard Institution, London

23. Carmona JP, Oliveira PJV, Lemos LJ (2016) Biostabilization of a sandy soil using enzymatic calcium carbonate precipitation. Procedia Eng 143:1301-1308

24. Cassagrande A (1947) Classification and identification of soils. Am Soc Civ Eng 113:901-930

25. Chandrasekhar S, Pramada P, Majeed J (2006) Effect of calcination temperature and heating rate on the optical properties and reactivity of rice husk ash. J Mater Sci 41:7926-7933

26. Chiet KTP, Kassim KT, Chen KB, Martula U, Yah CS, Arefnia A (2016). Effect of reagents concentration on biocementation of tropical residual soil. In: IOP conference series: materials science and engineering, vol 136, p 012030 https://doi. org/10.1088/1757-899x/136/1/012030

27. Daimary N, Bhattacharjee A, Goswami R (2016) Effect of rice husk ash on shear and consolidation of lateritic soil. In: Indian geotechnical conference IGC, 15-17

28. DeJong JT, Mortensen BM, Martinez BC, Nelson DC (2010) Biomediated Soil Improvement. Ecol Eng 36:197-210

29. DeJong JT, Fritzges MB, Nüsslein K (2006) Microbially induced cementation to control sand response to undrained shear. J Geotech Geoenviron Eng 132:1381-1392

30. Dekuyer A, Liang C, Shahin MA, Cord-Ruwisch R (2012). Calcium carbonate induced precipitation for soil improvement by urea hydrolyzing bacteria. In: Advances in civil, environmental and materials research, pp 26-30

31. Della VP, Kuhn I, Hotza D (2002) Rice husk ash as an alternate source for silica production. Mater Lett 57:818-821

32. Eberemu OA (2011) Consolidation properties of compacted lateritic soil treated with rice husk ash. Geomaterials 11:70-78

33. Hammes F, Nico B, Johan DV, Willy V, Steven DS (2003) Strainspecific ureolytic microbial calcium carbonate precipitation. Appl Environ Microbiol 69(8):4901-4909

34. Khaleghi M, Rowshanzamir MA (2017) An investigation on biological treatment of sandy soil. Assumpt Univ J Civil Eng 1(1):93-100. https://doi.org/10.22060/ceej.2017.12225.5152

35. Koteswara RD, Pranav PRT, Anusha M (2011) Stabilization of expansive soil with rice husk ash, lime and gypsum-an experimental study. Int J Eng Sci Technol 3(11):8076-8085

36. Lee ML, Soon NW, Tan CK, Hii SL (2012) Bio-mediated soil improvement under various concentrations of cementation reagents. Appl Mater 204-208:326-329

37. Little DN, Nair S (2009) Recommended practice for stabilization of subgrade soils and base materials. Final task Report for NCHRP Project 20-07
38. Little DN, Males EH, Prusinski JR, Stewart B (2000) Cementitious stabilization. Transportation Research Board

39. Mallela J, Quintus HV, Smith K (2004) Consideration of lime stabilized layers in mechanistic-empirical pavement design. The National Lime Association, Arlington

40. Fattah MY, Rahil FH, Al-Soudany KYH (2013) Improvement of clayey soil characteristics using rice husk ash. J Civ Eng Urban 3(1):12-18

41. Montoya BM, Dejong JT (2015) Stress strain behaviour of sands cemented by microbially induced calcite precipitation. J Geotech Geoenviron Eng 141(6):04015019

42. Mujedu KA, Adebara SA, Lamidi IO (2016) Influence of compaction delay on cement stabilized lateritic soil. In: International conference of science, engineering and environmental technology (ICONSEET), vol 1, no 5, pp 29-38. ISSN 0794-9650

43. Muntohar, S., and Hantoro, G., (2000). Influence of Rice Husk Ash and Lime on Engineering Properties of a Clayey Subgrade. Electronic Journal of Geotechnical Engineering, Vol. 5

44. Okafor FO, Okonkwo UN (2009) Effect of rice husk ash on some geotechnical properties of lateric soil. Leon Electron J Pract Technol 15:67-74

45. Osinubi KJ (1998) Influence of compaction delay on the properties of cement-stabilized lateritic soil. J Eng Res 6(1):13-25

46. Oyediran IA, Fadamoro OF (2015) Strength characteristics of genetically different rice and coconut husk ash compacted shale. Int J Geo Eng 6:10. https://doi.org/10.1186/S4070 3-015-0010-7

47. Oyediran IA, Fadamoro OF (2016) On the response of Ibese shale to rice and coconut husk ash treatment. In: Khabbaz $\mathrm{H}$, Hossain Z, Nam BH, Chen X (eds) Advances in pavement engineering and ground improvement: proceedings of the 4th geo-China international conference on sustainable civil infrastructures: innovative technologies for severe weathers and climate changes, 25-27 July, 2016. Shandong: American Society of Civil Engineers (ASCE). 258:35-43

48. Raheem AA, Bello OA, Makinde OA (2010) A comparative study of cement and lime stabilized lateritic interlocking blocks. Pac J Sci Technol 11(2):27-34

49. Ramezanianpour AA, Mahdi khani M, Ahmadibeni G (2009) The effect of rice husk ash on mechanical properties and durability of sustainable concretes. Int J Civ Eng 7(2)

50. Saravut J, Opas S, Pichai T (2012) An investigation of lateritic soil-cement for sustainable pavements. Indian J Sci Technol. ISSN: 0974-6846

51. Shahin M (2017) Innovative solutions for construction on problematic soils in civil infrastructure developments. In: Proceedings of the 2 nd world congress on civil, structural and environmental engineering (CSEE'17) Barcelona, Spain. ISSN: 2371-5294

52. Sharma A, Ramkrishnan R (2016) Study on effect of microbial induced calcite precipitates on strength of fine grained soils. Perspect Sci 8(2016):198-202

53. Shooshpasha I, Shirvan RA (2015) Effect of cement stabilization on geotechnical properties of sandy soils. Geomech Eng 8(1):17-31. https://doi.org/10.12989/gae.2015.8.1.017

54. Soltani N, Bahrami A, Pech-Canul MI, González LA (2015) Review on the physicochemical treatments of rice husk for production of advanced materials. Chem Eng J 264:899-935

55. Soon NW, Lee ML, Tan CK, Hii SL (2014) Factors affecting improvement in engineering properties of residual soil through microbial-induced calcite precipitation. J Geotech Geoenviron Eng 140(5):04014006-(1-11)

56. Whiffin VS, Leon AVP, Marien PH (2007) Microbial carbonate precipitation as a soil improvement technique. Geomicrobiol J 24(5):417-423 
57. Wong LS, Hashim, Ali F (2008) Strength and permeability of stabilized peat soil. J Appl Sci 8(21):3986-3990

58. Wykoff J (2016) soil stabilization with cement presented to: APWA Norcal conference 450 Civic Center St. Richmond, CA 94804. California Nevada Cement Association
Publisher's Note Springer Nature remains neutral with regard to jurisdictional claims in published maps and institutional affiliations. 